\title{
THERMOPHYSICAL PROPERTIES OF STAINLESS STEEL FOILS*
}

\section{Kenneth E. Wilkes, Joseph P. Strizak, and Fred J. Weaver}

Oak Ridge National Laboratory

\author{
and
}

John E. Besser and David L. Smith

Aladdin Industries, Inc.

Oak Ridge National Laboratory

P. O. Box 2008

Building 4508, MS 6092

Oak Ridge, Tennessee 37831-6092

(423) $574-5931$

FAX (423)-576-3894

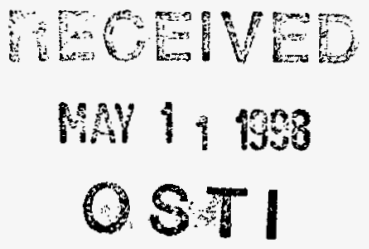

for publication in

Thermal Conductivity 24

Proceedings of the

24th International Thermal Conductivity Conference

Pittsburgh, Pennsylvania

October 26-29, 1997

${ }^{*}$ Research sponsored by Aladdin Industries, Inc. and the Office of Building Technology, State and Community Programs, U.S. Department of Energy under Contract No. DE-AC05-96OR22464 with Lockheed Martin Energy Research Corp. 


\section{DISCLAIMER}

This report was prepared as an account of work sponsored by an agency of the United States Government. Neither the United States Government nor any agency thereof, nor any of their employees, make any warranty, express or implied, or assumes any legal liability or responsibility for the accuracy, completeness, or usefulness of any information, apparatus, product, or process disclosed, or represents that its use would not infringe privately owned rights. Reference herein to any specific commercial product, process, or service by trade name, trademark, manufacturer, or otherwise does not necessarily constitute or imply its endorsement, recommendation, or favoring by the United States Government or any agency thereof. The views and opinions of authors expressed herein do not necessarily state or reflect those of the United States Government or any agency thereof. 


\begin{abstract}
Evacuated panel superinsulations with very high center-of-panel thermal resistances are being developed for use in refrigerators/freezers. Attainment of high resistances relies upon the maintenance of low vacuum levels by the use of stainless steel vacuum jackets. However, the metal jackets also present a path for heat conduction around the high resistance fillers. This paper presents results of a study of the impact of metal vacuum jackets on the overall thermal performance of vacuum superinsulations when incorporated into the walls and doors of refrigerators/freezers. Results are presented on measurements of the thermophysical properties of several types and thicknesses of stainless steel foils that were being considered for application in superinsulations. A direct electrical heating method was used for simultaneous measurements of the electrical resistivity, total hemispherical emittance, and thermal conductivity of the foils. Results are also presented on simulations of the energy usage of refrigerators/freezers containing stainless-steel-clad vacuum superinsulations.
\end{abstract}

\title{
INTRODUCTION
}

Evacuated panel superinsulations with very high thermal resistances are being developed for use in the walls and doors of refrigerators/freezers and potentially for other applications. Some superinsulations contain fillers that require high vacuums to minimize conduction by residual gases. In order to maintain these high vacuums, the vacuum jackets are made of stainless steel foils. Even though stainless steel has a low thermal conductivity, it presents a path for heat conduction around the high thermal resistances in the superinsulations.

The work reported here was undertaken as part of a Cooperative Research and Development Agreement (CRADA) between Aladdin Industries, which is developing superinsulations, and the Oak Ridge National Laboratory. The objective of the

Kenneth E. Wilkes, Joseph P. Strizak, and Fred J. Weaver, Metals and Ceramics Division, Oak Ridge National Laboratory, P. O. Box 2008, Bldg. 4508, MS-6092, Oak Ridge, TN 37831-6092

John E. Besser and David L. Smith, Aladdin Industries, Inc., P. O. Box 100255, Nashville, TN 37224 
CRADA was to evaluate the impact of heat conduction through stainless steel vacuum jackets on the overall thermal performance of superinsulations. 'This evaluation included measurement of the thermal conductivity of a number of types and thicknesses of stainless steel foils that were being considered for use in the superinsulations.

\section{EXPERIMENTAL PROCEDURES}

\section{APPARATUS AND SPECIMENS}

The apparatus used for the thermal conductivity measurements was originally developed for measurements of total hemispherical emittance, and meets the requirements of ASTM C 835 [1]. Specimens were clamped between two watercooled electrodes inside a water-cooled vacuum chamber and were heated by passage of a direct electric current. Platinum versus platinum-10 percent rhodium thermocouples, made of annealed $0.076 \mathrm{~mm}$ (0.003 in.) diameter wire, were spot welded to the specimens at selected positions along their lengths. The platinum-10 percent rhodium thermoelements were also used to measure the voltage drops along the specimens.

Six specimens were fabricated by Aladdin Industries from materials that they were considering for use in evacuated superinsulation panels. The alloys and nominal thicknesses are given in Table I. The specimens were made in the shape of dogbones with a $305 \mathrm{~mm}$ (12 in.) long uniform-width section. The eight thermocouples that were available in the apparatus were distributed along the length of the specimen to allow simultaneous measurement of the electrical resistivity, total hemispherical emittance, and thermal conductivity. Two of the thermocouples spanned the center $50.8 \mathrm{~mm}(2 \mathrm{in}$.) segment of the specimen, and the other six were placed near the ends of the uniform-width section where the temperature gradients were steep.

TABLE I. CHARACTERISTICS OF STAINLESS STEEL SPECIMENS

\begin{tabular}{|c|c|c||}
\hline Specimen & AISI Type & $\begin{array}{c}\text { Nominal } \\
\text { Thickness, mm (in.) }\end{array}$ \\
\hline \hline 1 & 304 & $0.305(0.012)$ \\
\hline 2 & 304 & $0.203(0.008)$ \\
\hline 3 & $201 \mathrm{~L}$ & $0.089(0.0035)$ \\
\hline 4 & 201 & $0.076(0.003)$ \\
\hline 5 & 321 & $0.076(0.003)$ \\
\hline 6 & 321 & $0.051(0.002)$ \\
\hline
\end{tabular}




\section{DATA REDUCTION}

A three-step data reduction procedure was used. First the electrical resistivity was obtained for the nearly isothermal central $50.8 \mathrm{~mm}$ segment, and the electrical resistivity versus temperature results were fitted to a second degree polynomial. The electrical resistivity was also measured at the other segments between voltage taps. These measurements confirmed the visual observation that the widths of the thin specimens were not as uniform as was desired. They showed that the thin specimens were slightly tapered with the ends being more narrow than the center (by as much as 2 percent). The measurements made near room temperature, where the results were not confounded by the temperature dependence of the resistivity, were used to quantify the variation of the width from one segment to another along the length of the specimen.

In the second step of data analysis, the total hemispherical emittance was obtained from the measurements on the central segment. A correction was applied to account for heat conduction along the specimen. This was done by fitting a cubic spline [2] to the measured temperature profile, calculating the temperature gradient at the ends of the center segment, and then calculating the conduction using literature values for the thermal conductivity [3]. The correction for conduction was never more than 3 percent (for the thickest specimens at the lowest temperatures), and was usually much less. The emittance versus temperature data were also fitted to a second degree polynomial.

In the third step of the data analysis, the thermal conductivity was estimated from the following differential equation:

$$
\frac{\mathrm{I}^{2} \rho}{\mathrm{A}}-\mathrm{P} \epsilon \sigma\left(\mathrm{T}^{4}-\mathrm{T}_{0}^{4}\right)+\lambda \mathrm{A} \frac{\mathrm{d}^{2} \mathrm{~T}}{\mathrm{dx}^{2}}=0
$$

where $\lambda$ is the thermal conductivity , $\epsilon$ is the total hemispherical emittance, $\rho$ is the electrical resistivity, $\mathrm{I}$ is the current, $\mathrm{A}$ is the cross-sectional area, $\mathrm{P}$ is the perimeter, $\mathrm{T}$ is the temperature at position $\mathrm{x}, \mathrm{T}_{0}$ is the temperature of the vacuum chamber walls, and $\sigma$ is the Stefan-Boltzmann constant. This equation assumes that the Thomson heat is negligible, that the temperature varies only along the length of the specimen (i.e., the long thin rod approximation), and that the thermal conductivity may be treated as a constant over the temperature range that exists between the two end thermocouples for a given test (usually less than about $35^{\circ} \mathrm{C}$ ).

A computer program was written to obtain the thermal conductivity from Equation 1. The core of the program was a finite-difference solution of Equation 1. The electrical resistivity and total hemispherical emittance were allowed to vary with temperature according to the second degree polynomials obtained in the first two steps of the data analysis. In addition to these factors, the specimen width (and hence crosssectional area and perimeter) was varied along the length of the specimen, as derived from the electrical resistivity measurements. The variation was treated as a constant width for each segment between voltage taps so that the heat generation for each segment was correct. The measured end temperatures were applied as boundary conditions, and an estimate of the thermal conductivity allowed the program to 
calculate a temperature profile along the specimen. The other part of the program was a least squares procedure in which the thermal conductivity was systematically varied until the best match was obtained between the measured and calculated temperature profiles. This direct numerical solution of the differential equation eliminated the many approximations that would be needed in order to obtain analytical solutions.

\section{RESULTS AND DISCUSSION}

\section{ELECTRICAL RESISTIVITY}

A series of measurements was made as the specimens were heated from room temperature to about $500{ }^{\circ} \mathrm{C}$ and then as they were cooled back to room temperature. Figure 1 shows the results for Type 304 Specimen 2, which are typical of the results on the other specimens. No differences were seen between the data obtained on heating and cooling. The regression curve through the data is nearly parallel to the CINDAS recommended values for Type 304 stainless steel [4], but is higher by about 1.5 to 2 percent. For reference, Figure 1 also shows the CINDAS recommended values for the other stainless steels - Types 321 and 201 [4,5].

The individual data points are compared with CINDAS values in Figure 2. The data for Specimens 1 and 2 (Type 304) are within 2 percent of the CINDAS values; those for Specimens 5 and 6 (Type 321) are within 3 percent. Specimen 3 data (Type 201L) are within 0.5 percent, but the Specimen 4 data (Type 201) are 3 to 5 percent

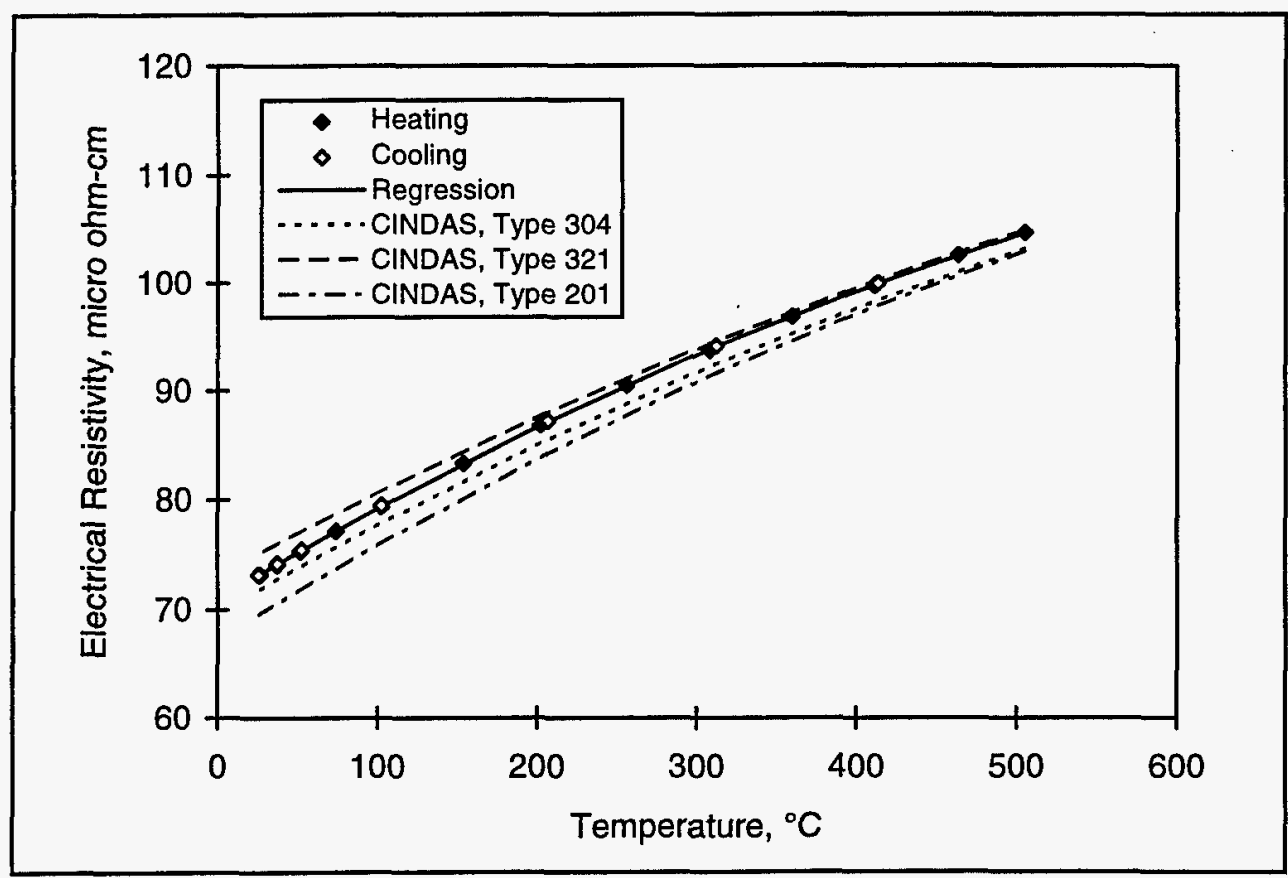

Figure 1. Electrical Resistivity of Type 304 Stainless Steel Specimen 2. CINDAS recommended values for Types 201, 304, and 321 stainless steel in the solutionannealed condition are also shown. 


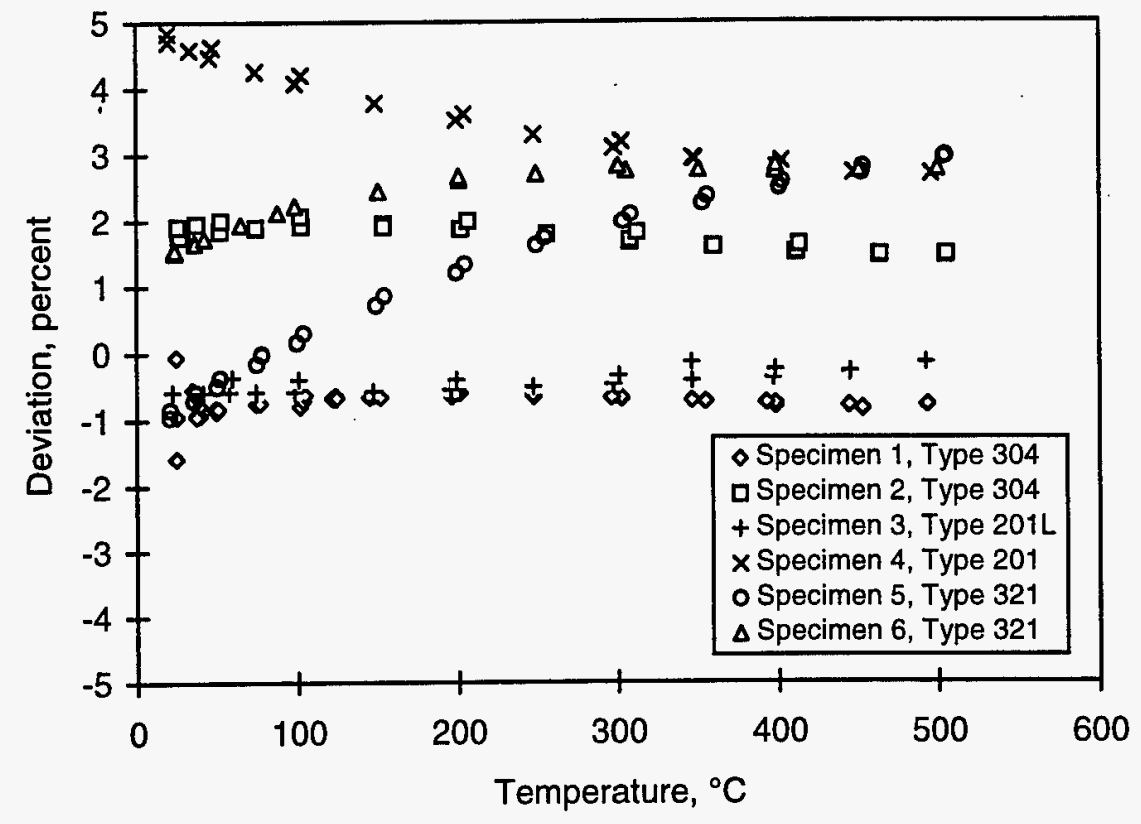

Figure 2. Deviation of Electrical Resistivity of Stainless Steel Foils from CINDAS Recommended Values.

higher than the CINDAS values. Except for Specimens 4 and 5, the deviations for a particular specimen are nearly constant, and are mostly positive. These nearly constant percentage offsets could be due to an uncertainty in the specimen thickness. Thicknesses were measured to the nearest $0.0013 \mathrm{~mm}(0.00005 \mathrm{in}$.), and this would lead to an uncertainty in the resistivity of 0.4 percent for the thickest specimen and 2.5 percent for the thinnest one. The surface roughness can contribute to a measured thickness that is larger than the average value, since a micrometer measures the distance between the peaks on the two sides of the specimen. The peak-to-valley surface roughness of Specimen 4 was determined to be about $0.0014 \mathrm{~mm}$, which is about 1.8 percent of the specimen thickness. Another reason that the measured resistivities of many of the specimens are higher than the CINDAS values could be differences in heat treatment. The CINDAS values are for the solution-annealed condition, while the foil specimens are most likely in the cold-worked condition. Tye, et al. [6] found that the resistivity of Type 301 stainless steel in the hardened condition was about 10 percent higher than in the annealed condition at room temperature. At higher temperatures, the differences were smaller.

\section{EMITTANCE}

Emittance results for the two Type 304 specimens are shown in Figure 3, and results for the Type 201 and 321 specimens are shown in Figure 4. The emittances of Specimens 2-6 differed by only about 5 percent, while that of Specimen 1 was about 38 percent higher. These differences are no doubt due to the surface finishes. 


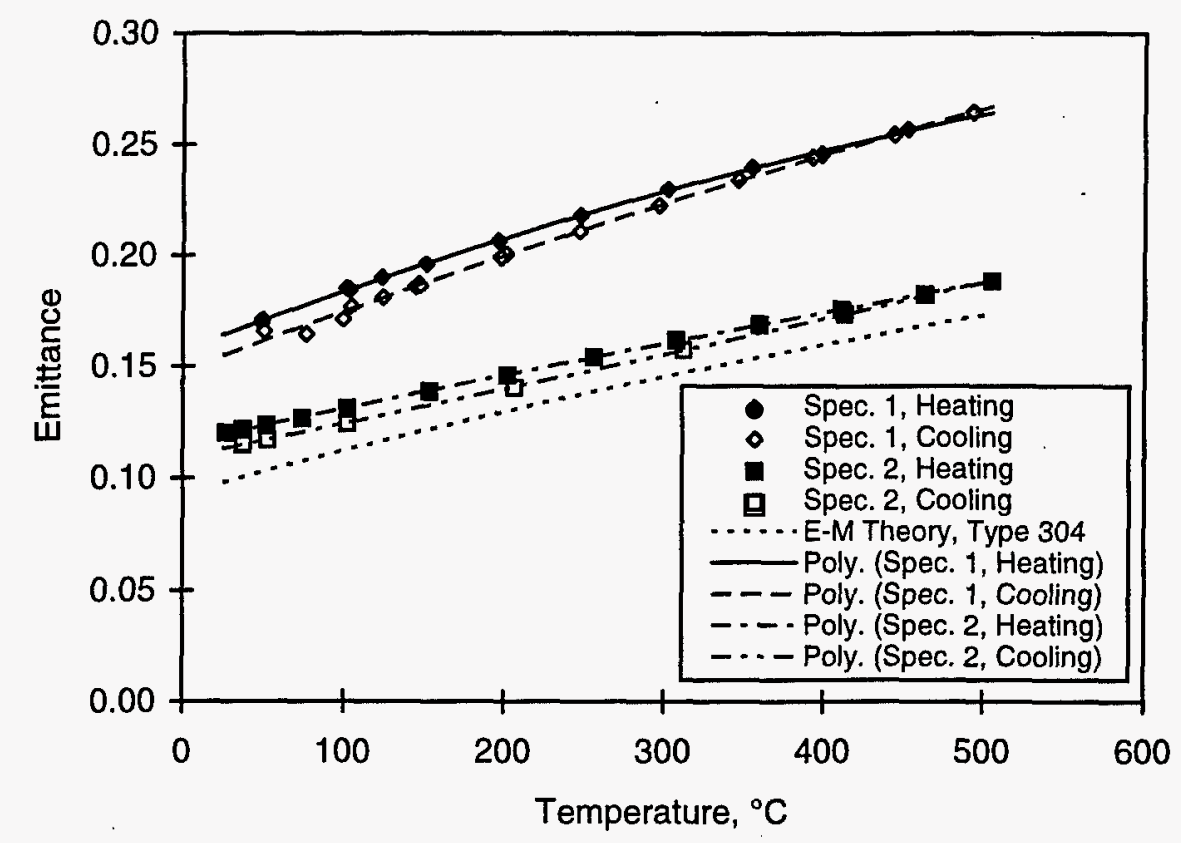

Figure 3. Total Hemispherical Emittance of Type 304 Stainless Steel Foils. Curves labeled "Poly." are the polynomial regressions.

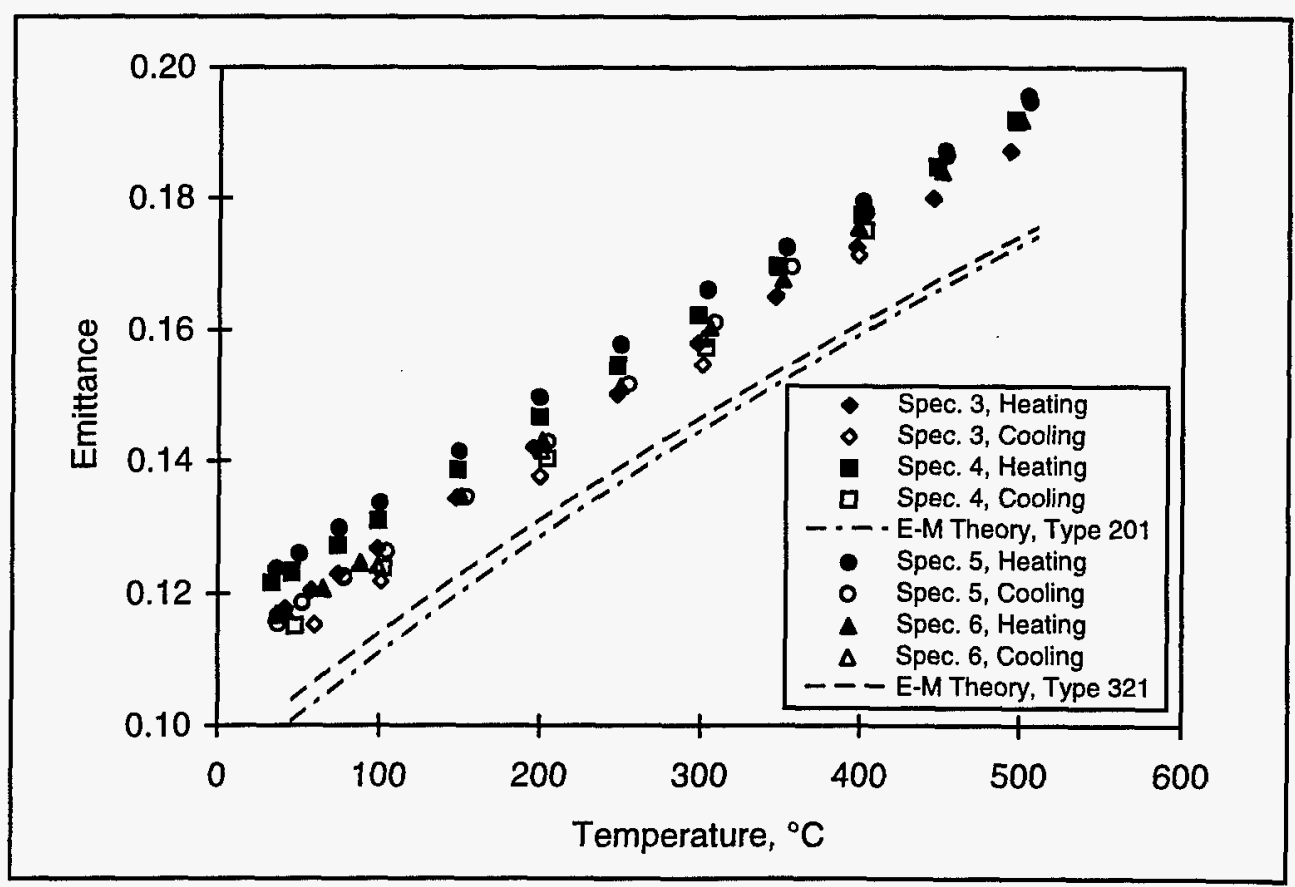

Figure 4. Total Hemispherical Emittance of Type 201 and 321 Stainless Steel Foils. Specimen 3 is Type 201L, Specimen 4 is Type 201, and Specimens 5 and 6 are Type 321. 
Specimens 2-6 were noticeably brighter than Specimen 1, and microscopic examination showed that Specimen 1 had a matte finish while the other specimens had a brighter finish characterized by series of perpendicular grooves. Exposure of the specimens to $500{ }^{\circ} \mathrm{C}$ in vacuum produced a consistent lowering of the emittance, by 3 to 8 percent near room temperature. There were no visible changes in the surfaces after heating.

The total hemispherical emittance for optically flat, uncontaminated surfaces can be predicted from electromagnetic theory by:

$$
\epsilon=0.766(\rho \mathrm{T})^{1 / 2}-[0.309-0.0889 \ln (\rho \mathrm{T})] \rho \mathrm{T}-0.0175(\rho \mathrm{T})^{3 / 2}
$$

where $\rho$ is the electrical resistivity in ohm-cm and $T$ is the temperature in $K$ [7]. Figures 3 and 4 show the theoretical curves calculated using the CINDAS recommended electrical resistivities. The experimental and theoretical curves show nearly the same variations with temperature. The emittances for Specimens 2-6 were only 15 to 22 percent higher than the theoretical values at room temperature before heating, 8 to 12 percent higher at $500^{\circ} \mathrm{C}$, and 11 to 15 percent higher after cooling to room temperature.

\section{THERMAL CONDUCTIVITY}

Thermal conductivity results are plotted in Figure 5, along with the CINDAS recommended curves for Types 201, 304, and 321 stainless steels (the recommended curves for Types 201 and 304 are nearly identical). Thermal conductivity data are reported over a more limited temperature range than for electrical resistivity and emittance because of two factors. At temperatures below about $50^{\circ} \mathrm{C}$ the temperature differences along the specimen were considered to be too small. As the temperatures were increased, the temperature profiles became flatter in the middle and steeper at the ends, so that the measured temperature profiles were not defined well enough to obtain thermal conductivities at the high end of the temperature range. Flattening of the temperature profiles with increasing temperature is characteristic of this method. The degree of flattening depends upon the specimen geometry and was especially severe for the very thin specimens used in this study.

All the data, except for that on Specimen 4, fall within a band about \pm 7 percent wide. In general, the thermal conductivity increases slightly faster with temperature than the recommended curves, and the data for most of the specimens are systematically lower than the recommended curves. For example, the data for the two Type 304 specimens are low by about 10 to 15 percent at the lower end of the temperature range and are somewhat closer at the high end. The data for Specimen 4 (Type 201) are low by 15 to 23 percent, but results for the other three specimens are within about 5 to 10 percent of the recommended values. The thermal conductivity data for all specimens averaged about 8 percent lower than the CINDAS values.

The bias towards low values may be due to a number of factors. Tye, et al. [6] have shown that Type 301 stainless steel in the hardened condition has a thermal conductivity that is lower than that for the annealed condition by about 10 percent near 


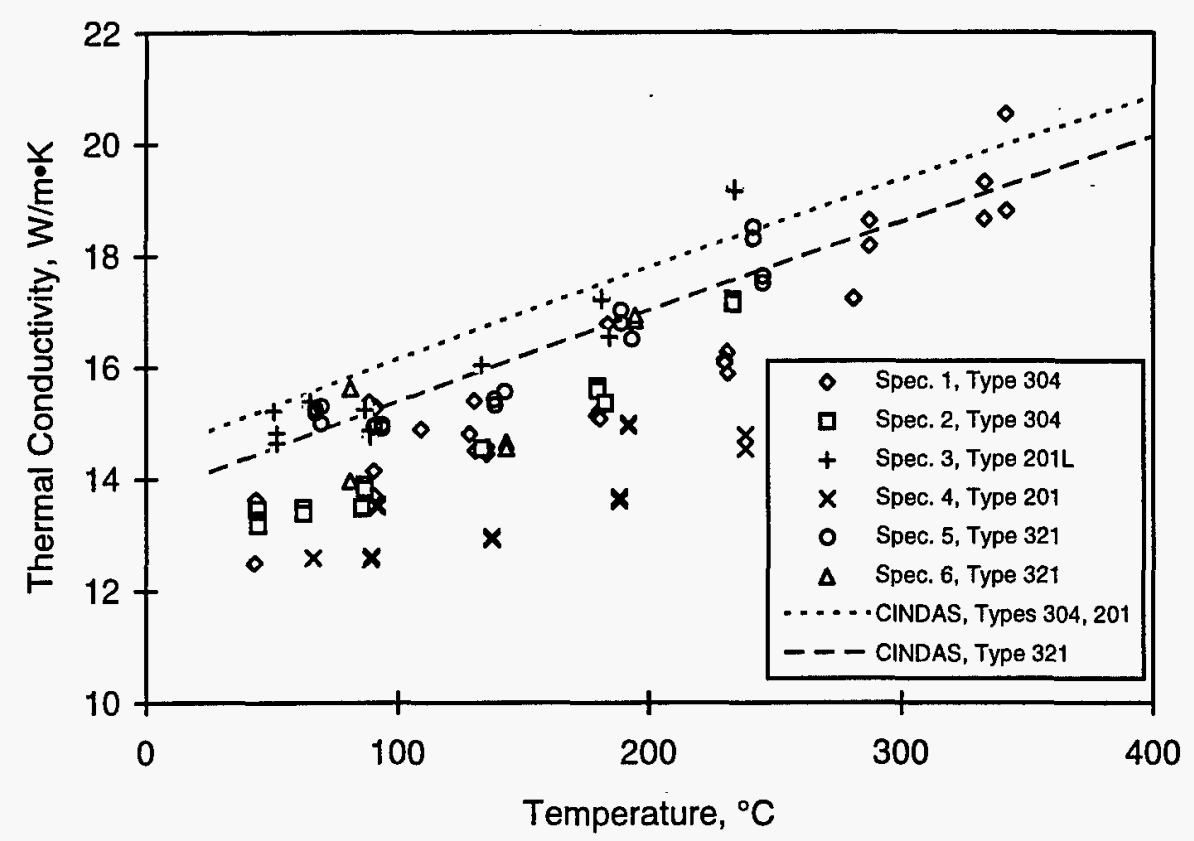

Figure 5. Thermal Conductivity of Stainless Steel Foils. CINDAS recommended values for the solution-annealed condition are also shown.

room temperature, with the difference between the two conditions decreasing as the temperature is increased. Since the CINDAS recommended values are for the solution-annealed condition while the rolled foils are most likely in a cold-worked condition, the heat treatment condition may explain at least part of the bias toward low values.

A second factor that was mentioned in connection with the electrical resistivity data is the uncertainty in specimen thickness, both because of the resolution of the micrometer and because of the significant degree of surface roughness. For the thin specimens, the total bias due to the thickness could be as high as 5 percent, but would be less for the thicker Type 304 specimens.

There are a number of additional sources of uncertainty that arise because of the complex method of extracting the thermal conductivity from the measured temperature profiles. Since the thermal conductivities for Specimen 4 were so much lower than the recommended curve, we performed an analysis of the sensitivity of the results to several parameters that are inputs to the data analysis to illustrate these other uncertainties. The data point at the mid-range temperature of $137^{\circ} \mathrm{C}$ was selected for analysis. Table II shows the change in calculated thermal conductivity due to assumed variations in a number of parameters. These magnitudes of the variations in parameters are arbitrary and are not necessarily an estimate of the actual uncertainty. The first parameter is the uncertainty in the location of key thermocouples. Here, the distance between the two end thermocouples (where the temperature gradient is steepest) was changed by 1 percent; this resulted in an 0.8 percent change in thermal conductivity. Next, the measured temperatures were randomly perturbed by $\pm 1{ }^{\circ} \mathrm{C}$; 
TABLE II. SENSITIVITY OF CALCULATED THERMAL CONDUCTIVITY TO CHANGES IN SYSTEM PARAMETERS

\begin{tabular}{||l|c|}
\hline \multicolumn{1}{|c|}{ Parameter change } & Change in thermal conductivity \\
\hline \hline $\begin{array}{l}\text { Change distance between two end } \\
\text { thermocouples by } 1 \%\end{array}$ & $0.8 \%$ \\
\hline Perturb temperatures randomly by $1{ }^{\circ} \mathrm{C}$ & $2.3 \%$ \\
\hline Change emittance by $1 \%$ & $11 \%$ \\
\hline Change electrical resistivity by $1 \%$ & $12 \%$ \\
\hline $\begin{array}{l}\text { Change width of two segments at each end by } \\
1 \%\end{array}$ & $11 \%$ \\
\hline
\end{tabular}

Note: case examined is data point for Specimen 4 at $137^{\circ} \mathrm{C}$.

this resulted in a 2.3 percent change in thermal conductivity. Both of these changes are considered to be overestimates of the actual uncertainty.

Other uncertainties are related to the balance of the heat generation, radiation, and conduction terms in Equation 1. The thin foils used here have a much more unfavorable cross-section for measurements of thermal conductivity than the thicker strips, rods, and tubes that are normally used with this type of measurement. Conduction is controlled by the cross-sectional area, but heat losses by radiation are controlled by the perimeter. These specimens have high ratios of perimeter to crosssectional area, equivalent to wires having diameters of 0.15 to $0.6 \mathrm{~mm}(0.006$ to 0.023 in.), making radiation losses very significant. Table II shows that a change of 1 percent in the emittance results in an 11 percent change in the conductivity. A change of 1 percent in the electrical resistivity would change the thermal conductivity by 12 percent. As was noted above, the specimen width was not exactly uniform, but was slightly more narrow near the ends than in the middle. Changing the widths of the two segments at each end by 1 percent results in an 11 percent change in conductivity. Thus a small uncertainty in any of these three factors results in a much larger uncertainty in the thermal conductivity. The nonuniform specimen width had a large impact on the data. Since the ends were more narrow, the heat generation was larger near the ends than in the middle. The result was that at high temperatures, the temperature profiles became distorted so that the center was no longer the hottest location, and the temperature gradients at the ends became abnormally steep. Specimen 4 had the largest nonuniformity of width, and this may have caused the measured thermal conductivities to be artificially low.

A possible method to reduce the uncertainties in the thermal conductivity would be to perform measurements with both long and short specimens as has been done by Taylor [8]. Since Taylor measured the temperature profile optically, he was able to alter the specimen length at will and still obtain complete temperature profiles. With our apparatus, we were limited to temperature measurements at a number of fixed locations. Nevertheless, we attempted to do a long specimen/short specimen experiment with Specimen 4. After the long-specimen runs, the specimen was 
removed from the apparatus and was shortened. Three new thermocouples were added to give a $76 \mathrm{~mm}$ ( $3 \mathrm{in}$.) long test section, and the specimen was reinstalled in the apparatus. Unfortunately, during the run a leak in the vacuum system caused the surface to oxidize, thereby changing the emittance from the long-specimen run and preventing thermal conductivity data from being obtained. Although this experiment failed, we plan to try some variation of this procedure for future measurements.

\section{APPLICATION TO REFRIGERATORS}

The thermal conductivity data were extrapolated to room temperature and the resulting values were used to estimate the energy savings that would be obtained by incorporating stainless-steel-clad vacuum superinsulations in the walls and doors of refrigerators. Refrigerator energy usage was simulated using the EPA Refrigerator Analysis (ERA) computer program [9]. This program combines an analysis of the refrigeration load requirements on the cabinet with a simulation of the capacity and efficiency of the refrigeration cycle. The program has built into it the capability of analyzing the effects of metal-clad vacuum insulations.

Simulations were performed for a common 18 cubic foot top-mount refrigerator, using specifications as given by EPA [10]. The wall insulation for the base case was polyurethane foam with a thermal conductivity of $0.018 \mathrm{~W} / \mathrm{m} \cdot \mathrm{K}$. Some parameters given in Ref. 10 were modified slightly to allow an ambient temperature that is more representative of room temperatures, and to include a door opening schedule. With these changes, the annual energy usage was calculated to be $671 \mathrm{kWh}$.

Figure 6 shows the results of simulations where vacuum superinsulations were partially substituted for the polyurethane foam. The vacuum insulations were taken to be $25.4 \mathrm{~mm}$ (1 in.) thick and to cover 60 percent of the wall and door areas. Parameters varied in this figure are the effective thermal conductivity of the vacuum insulation filler, the thermal conductivity of the vacuum cladding material, and the thickness of the cladding. The simulations show that heat conduction around the edges of the vacuum insulation for cladding thicknesses of 0.05 to $0.1 \mathrm{~mm}(0.002$ to 0.004 in.), as were being considered for this application, reduce the potential energy savings by 12 to 25 percent. At these thicknesses, a \pm 15 percent variation in cladding thermal conductivity results in less than $a \pm 5$ percent effect on the energy savings due to the vacuum insulations.

\section{SUMMARY AND CONCLUSIONS}

A direct electrical heating method has been used for simultaneous measurements of the electrical resistivity, total hemispherical emittance, and thermal conductivity of stainless steel foils that are being considered for use as claddings for vacuum superinsulations. Measurements were made on Types 201, 201L, 304, and 321 stainless steels at foil thicknesses from 0.051 to $0.30 \mathrm{~mm}(0.002$ to $0.012 \mathrm{in}$.). Electrical resistivities ranged from 1 percent below to 5 percent above CINDAS recommended values. Emittances of five of the six specimens were very similar and were within about 22 percent of theoretical values. A new data reduction method, 


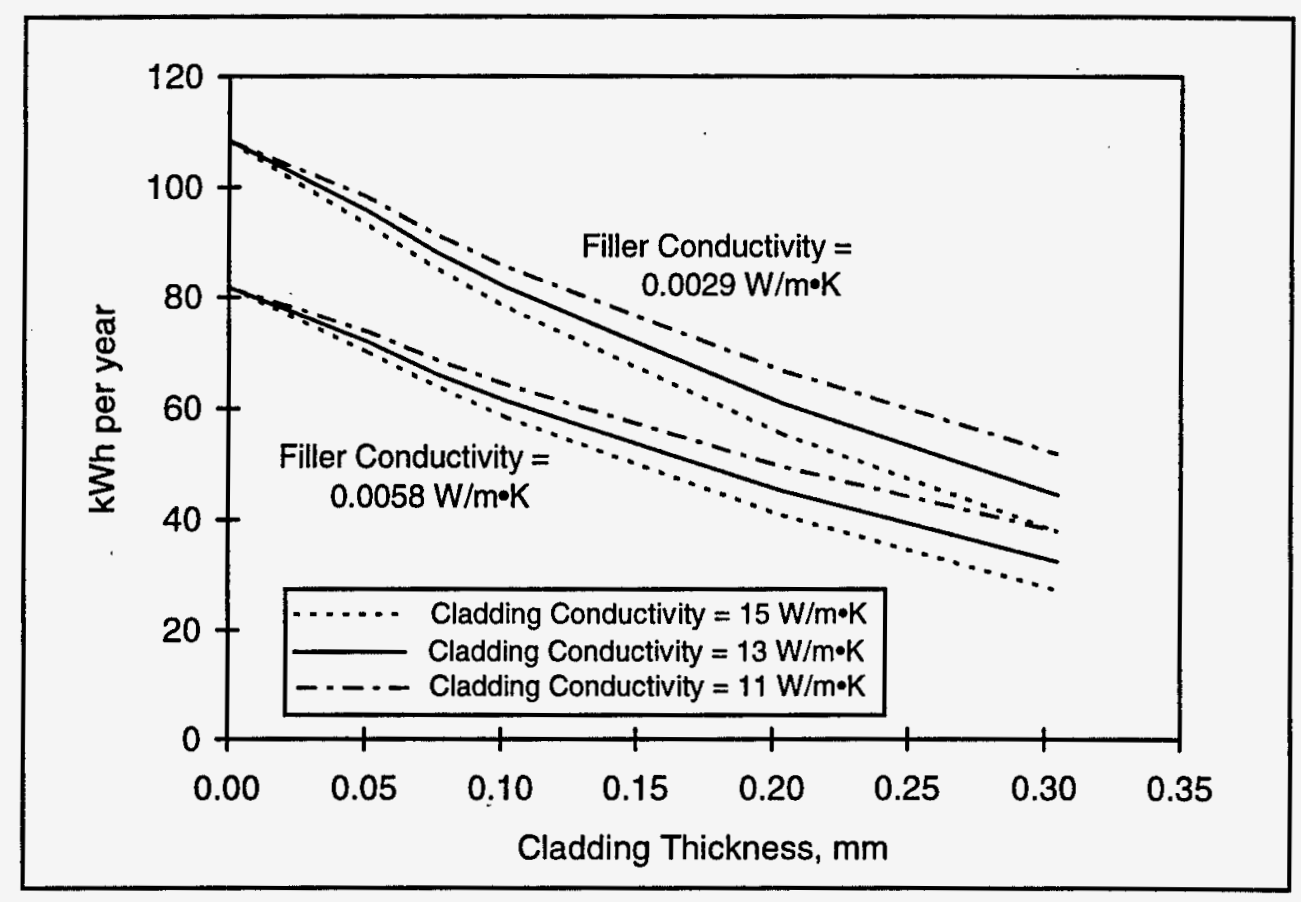

Figure 6. Simulated Annual Energy Savings for a Typical Refrigerator due to Addition of $25.4 \mathrm{~mm}$ Thick Vacuum Superinsulations at 60 percent Area Coverage.

consisting of a finite-difference solution of the governing differential equation and a least-squares matching of calculated and measured temperature profiles, was developed for extraction of the thermal conductivity from the measured data. It incorporates the temperature dependence of the electrical resistivity and emittance without any approximations. Thermal conductivity data for five of the six specimens fell within a band that was \pm 7 percent wide. The thermal conductivity data for all specimens averaged 8 percent lower than CINDAS values, and the thermal conductivity of one specimen averaged 20 percent low. Measured thermal conductivities were found to be very sensitive to small variations in specimen width. Simulations of refrigerators containing stainless-steel-clad vacuum insulations showed that $a \pm 15$ percent uncertainty in thermal conductivity of the cladding results in less than $a \pm 5$ percent change in energy savings.

\section{ACKNOWLEDGEMENTS}

This research was sponsored by Aladdin Industries, Inc. and by the U.S. Department of Energy, Office of Building Technology, State and Community Programs, under contract number DE-AC05-96ORR22464 with the Oak Ridge National Laboratory, managed by Lockheed Martin Energy Research Corp. 


\section{REFERENCES}

1. C 835, "Standard Test Method for Total Hemispherical Emittance of Surfaces From 20 to $1400{ }^{\circ} \mathrm{C}$," in 1996 Annual Book of ASTM Standards, Vol. 04.06, American Society for Testing and Materials, Philadelphia, pp. 405-414.

2. Burden, R. L. and J. D. Faires, 1989. Numerical Analysis, 4th Ed., PSW-KENT Publishing Co., Boston, pp. 126-144.

3. Graves, R. S., T. G. Kollie, D. L. McElroy, and K. E. Gilchrist, 1991. "The Thermal Conductivity of AISI 304L Stainless Steel," International Journal of Thermophysics, Vol. 12, pp. 409-415.

4. Chu, T. K. and C. Y. Ho, 1978. "Thermal Conductivity and Electrical Resistivity of Eight Selected AISI Stainless Steels," Thermal Conductivity 15, Proceedings of the 15th International Thermal Conductivity Conference, V. V. Mirkovick, Ed., Plenum Press, New York, pp. 79-104.

5. Bogaard, R. H., March 1997. Private communication to K. E. Wilkes, provided the recommended values for AISI Type 201 stainless steel.

6. Tye, R. P., R. W. Hayden, and S. C. Spinney, 1977. "Thermal Conductivity of Selected Alloys at Low Temperatures," Advances in Cryogenic Engineering, Vol. 22, K. D. Timmerhaus, R. P. Reed, and A. F. Clark, Eds., Plenum Press, New York, pp. 136-144.

7. Parker, W. J. and G. L. Abbott, 1963. Symposium on Thermal Radiation of Solids, ed. by S. Kateoff, NASA SP-55, pp. 11-28.

8. Taylor, R. E., 1984. "Thermophysical Property Determinations Using Direct Heating Methods," in Compendium of Thermophysical Property Measurement Methods, Vol. 1, Survey of Measurement Techniques, K. D. Maglić, A. Cezairliyan, and V. E. Peletsky, Eds., Plenum Press, New York, pp. 125-167.

9. "EPA Refrigerator Analysis (ERA) Program, User's Manual, Version 1.0," 1993. EPA-430-R-93-007, U.S. Environmental Protection Agency.

10. "Multiple Pathways to Super-Efficient Refrigerators," 1993. EPA-430-R-93-008, U.S. Environmental Protection Agency, Global Change Division, Office of Atmospheric Programs, Washington, D.C. 

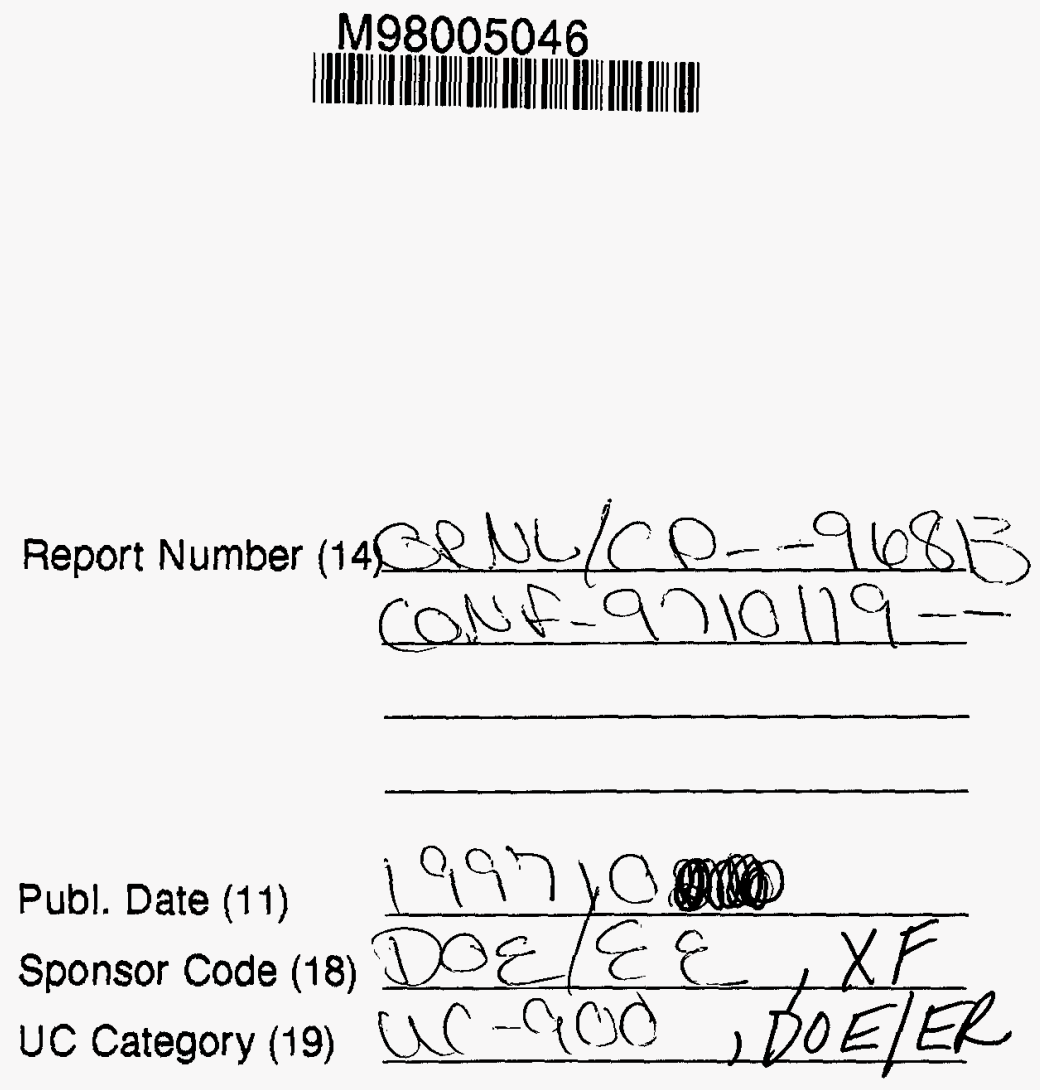